\title{
Efeito da ractopamina e de métodos de formulação de ração sobre o desempenho e as características de carcaça de leitoas em terminação
}

\author{
[Effect of ractopamine and methods of diet formulation on performance and carcass \\ characteristics of finishing gilts] \\ F.A. Pereira ${ }^{1}$, D.O. Fontes ${ }^{2 *}$, C.H.F. Vasconcellos ${ }^{3}$, F.C.O. Silva ${ }^{4}$, M.A. Silva ${ }^{2}$, \\ P.C. Marinho ${ }^{1}$, C.L.C. Arouca ${ }^{1}$, G.M. Salum ${ }^{1}$ \\ ${ }^{1}$ Aluno de pós-graduação - EV-UFMG - Belo Horizonte, MG \\ ${ }^{2}$ Escola de Veterinária - UFMG - Belo Horizonte, MG \\ ${ }^{3}$ Instituto Federal de Mato Grosso - Cuiabá, MT \\ ${ }^{4}$ EPAMIG - CTZM - Viçosa, MG
}

\begin{abstract}
RESUMO
Avaliou-se o efeito da ractopamina e de diferentes métodos de formulação de dietas sobre o desempenho e as características de carcaça de leitoas em terminação. Foram utilizadas 60 leitoas, híbridas comerciais, distribuídas em delineamento experimental de blocos ao acaso, em esquema fatorial 2x3, sendo dois níveis de ractopamina e três métodos de formulação de dietas. Houve interação de métodos de formulação versus ractopamina para ganho de peso diário, peso corporal, conversão alimentar e taxa de deposição de carne magra (TDCM) na avaliação de carcaça in vivo por ultrassom. A dieta formulada com alta proteína bruta proporcionou maior consumo de dieta (CRD), de lisina (CLD), ganho de peso diário (GPD) e peso corporal final. A suplementação de ractopamina não influenciou o CRD e o CLD, entretanto aumentou o GPD. O método de formulação da dieta não influenciou as características de carcaça aos 28 dias, enquanto a suplementação de ractopamina reduziu a espessura de toucinho, aumentou a profundidade de lombo e o rendimento de carne magra. A dieta formulada com alta proteína bruta proporcionou melhores resultados de desempenho e taxa de deposição de carne magra na carcaça de leitoas em terminação, suplementadas com ractopamina.
\end{abstract}

Palavras-chave: leitoa, ractopamina, lisina, desempenho, carcaça

\begin{abstract}
The effect of ractopamine supplementation and feed formulation methods was evaluated on performance and carcass characteristics of finishing gilts. Sixty animals were allotted in a completely randomized block experimental design, in a $2 \times 3$ factorial scheme - ractopamine ( 0 and 5ppm) $X$ three feed formulation methods. Interactions between feed formulation method and ractopamine for daily weight gain (DWG), body weight, feed:gain (DFG), and lean carcass meat deposition (LCMD) were by in vivo carcass evaluation using ultrasound observed. Daily feed intake (DFI), lysine intake (DLI), DWG, and final body weight were higher for diets with high protein level. Ractopamine supplementation did not affect feed intake, and lysine intake, but increased daily weight gain. Feed formulation method affected carcass characteristics recorded at 28 days, while ractopamine supplementation reduced backfat thickness, increased muscle depth, and lean carcass proportion of the gilts. Ractopamine improved performance and carcass characteristics of finishing gilts and feed formulation methods affected performance and carcass characteristics. Better performance and higher lean carcass deposition were observed for finishing gilts fed high protein level diets supplemented with ractopamine.
\end{abstract}

Keywords: gilts, ractopamine, performance, carcass

Recebido em 21 de janeiro de 2010

Aceito em 22 de dezembro de 2010

Autor para correspondência (corresponding author)

E-mail:dalton@vet.ufmg.br 


\section{Pereira et al.}

\section{INTRODUÇÃO}

A alimentação de suínos em fase de terminação representa o maior volume de ração consumido dentro de um sistema de produção. Algumas medidas que proporcionem melhorias em eficiência alimentar dos animais podem ter grande impacto no consumo total de ração do sistema e consequente redução do custo total de produção. Dentre os partidores de nutrientes em dietas para suínos em terminação, a ractopamina se destaca. Os objetivos são melhor ganho de peso, eficiência alimentar e qualidade de carcaça.

A eficiência da ractopamina em proporcionar melhoria do desempenho e das características de carcaça dos suínos está condicionada ao aumento do nível de lisina na ração (Xiao et al., 1999; Marinho et al., 2005a). A concentração de lisina na proteína depositada por suínos que consumiram ração suplementada com ractopamina aumenta de 6,8 para 7,2\% (Schinckel et al., 2003). Assim, segundo esses autores, a relação de aminoácidos proposta para proteína ideal pode não ser suficiente para atender às exigências de suínos que consumiram ração contendo ractopamina. Desse modo, têm sido recomendados alguns ajustes nutricionais, principalmente na proteína bruta e nos aminoácidos. Esses ajustes podem ser obtidos utilizando-se diferentes métodos de formulação de ração.

Na prática, tem sido recomendado aumentar o nível de lisina, por meio da adição de lisina sintética, com ou sem ajuste dos demais aminoácidos essenciais para manter a relação ideal, o que pode limitar as ações da ractopamina. O objetivo deste trabalho foi verificar os efeitos da suplementação de ractopamina e de três métodos de formulação de ração sobre o desempenho e a qualidade de carcaça de suínos em fase de terminação.

\section{MATERIAL E MÉTODOS}

O experimento foi realizado durante os meses de fevereiro e março de 2004. Os animais foram alojados em galpão de alvenaria com piso de concreto e coberto com telhas de barro. As baias continham comedouros semiautomáticos, bebedouros tipo chupeta e dispunham de uma área de $1,87 \mathrm{~m}^{2} /$ animal. Foi utilizado um termômetro de máxima e mínima, no interior do galpão, à altura do dorso dos animais, para registro diário da temperatura, durante todo o período experimental. As temperaturas, mínima e máxima, verificadas no período foram, respectivamente, $19 \pm 2^{\circ} \mathrm{C}$ e $28 \pm 2,8^{\circ} \mathrm{C}$.

Foram utilizadas 60 leitoas, híbridas comerciais, de linhagens selecionadas geneticamente para alta deposição de carne magra, originadas do cruzamento da fêmea Camborough $22 \AA$ com o macho AGPIC $412{ }^{\circledR}$ da Agroceres Pic, com peso inicial de 84,96 $\pm 0,54 \mathrm{~kg}$, distribuídas em delineamento experimental de blocos ao acaso, em esquema fatorial $2 \times 3$, sendo dois níveis de suplementação de ractopamina (0 e 5ppm) e três métodos de formulação de ração para se obter o nível de $0,87 \%$ de lisina digestível (adição da lisina industrial sem ajuste dos demais aminoácidos essenciais para proteína ideal; adição de lisina e outros aminoácidos industriais - ajuste para proteína ideal; e aumento do nível de inclusão do farelo de soja - alto nível de proteína bruta). Utilizaram-se cinco repetições e dois animais por unidade experimental. Na distribuição dos animais, foi adotado como critério o peso inicial. Os animais foram identificados individualmente e avaliados em dois períodos: aos 21 e aos 28 dias de tratamento.

As dietas experimentais, à base de milho e farelo de soja, formuladas para atender às exigências mínimas estabelecidas por Rostagno et al. (2000) (Tab. 1), foram suplementadas com vitaminas, minerais e aminoácidos. As relações entre os aminoácidos essenciais digestíveis e a lisina digestível para proteína ideal foram estabelecidas de acordo com PIC (1999). O teor de 0,87\% de lisina digestível (LD) foi estabelecido porque os animais tratados com ractopamina devem consumir 30\% a mais de lisina para atingirem resultados significativos de desempenho e qualidade de carcaça (Mitchell et al., 1991; Xiao et al., 1999). O teor de $0,87 \%$ de LD foi obtido por três diferentes métodos de formulação de ração: por meio da adição de lisina-HCl (sem ajuste dos demais aminoácidos essenciais para a proteína ideal), da adição de lisina-HCl e de aminoácidos sintéticos (com ajuste para proteína ideal), bem como da maior inclusão de farelo de soja (alta proteína bruta), sendo suplementadas ou não com ractopamina.

Nas dietas formuladas utilizando-se o conceito de proteína ideal, foi utilizada a relação 
aminoacídica de 62, 57 e 18\%, respectivamente, para treonina, metionina+cistina e triptofano em relação à lisina, (PIC, 1999). As dietas experimentais e a água foram fornecidas à vontade durante todo o período experimental.

As dietas experimentais e as sobras foram pesadas duas vezes por semana durante todo o período experimental, enquanto os animais foram pesados, individualmente, no início, aos 21 dias e ao final do período experimental (28 dias), para se determinar o ganho de peso diário (GPD), a conversão alimentar (CA), o consumo de ração diário (CRD) e o consumo de lisina digestível diário (CLD).

Tabela 1. Composição centesimal e valores nutricionais calculados nas dietas usadas para suínos

\begin{tabular}{|c|c|c|c|c|c|c|}
\hline \multirow[b]{2}{*}{ Ingrediente } & \multicolumn{6}{|c|}{ Método de formulação de ração } \\
\hline & $\begin{array}{c}\text { Sem ajuste } \\
\text { aminoácidos }\end{array}$ & $\begin{array}{c}\text { Sem } \\
\text { ajuste aas } \\
+ \text { RAC }\end{array}$ & $\begin{array}{c}\text { Proteína } \\
\text { ideal }\end{array}$ & $\begin{array}{c}\text { Proteína } \\
\text { ideal } \\
+\mathrm{RAC}\end{array}$ & $\begin{array}{c}\text { Alta } \\
\text { proteína } \\
\text { bruta }\end{array}$ & $\begin{array}{c}\text { Alta } \\
\text { proteína }+ \\
\text { RAC }\end{array}$ \\
\hline Milho & 75,63 & 75,63 & 75,63 & 75,63 & 66,33 & 66,33 \\
\hline Farelo de soja & 21,11 & 21,11 & 21,11 & 21,11 & 30,20 & 30,20 \\
\hline Fosfato bicálcico & 1,19 & 1,19 & 1,19 & 1,19 & 1,13 & 1,13 \\
\hline Calcário & 0,82 & 0,82 & 0,82 & 0,82 & 0,79 & 0,79 \\
\hline Sal & 0,40 & 0,40 & 0,40 & 0,40 & 0,40 & 0,40 \\
\hline Óleo de soja & 0,00 & 0,00 & 0,00 & 0,00 & 0,30 & 0,30 \\
\hline Premix vitamínico ${ }^{1}$ & 0,30 & 0,30 & 0,30 & 0,30 & 0,30 & 0,30 \\
\hline Premix mineral $^{2}$ & 0,10 & 0,10 & 0,10 & 0,10 & 0,10 & 0,10 \\
\hline Tylan 100 & 0,08 & 0,08 & 0,08 & 0,08 & 0,08 & 0,08 \\
\hline Suplemento de cobre ${ }^{3}$ & 0,04 & 0,04 & 0,04 & 0,04 & 0,04 & 0,04 \\
\hline Paylean $^{\circledR}$ & 0,00 & 0,025 & $\mathbf{0 , 0 0}$ & 0,025 & 0,00 & 0,025 \\
\hline Inerte & 0,069 & 0,044 & 0,037 & 0,012 & 0,325 & 0,30 \\
\hline Lisina & 0,261 & 0,261 & 0,261 & 0,261 & 0,00 & 0,00 \\
\hline Treonina & 0,00 & 0,00 & 0,026 & 0,026 & 0,00 & 0,00 \\
\hline Metionina & 0,00 & 0,00 & 0,005 & 0,005 & 0,00 & 0,00 \\
\hline Total & 100,00 & 100,00 & 100,00 & 100,00 & 100,00 & 100,00 \\
\hline \multicolumn{7}{|c|}{ Valores nutricionais calculados ${ }^{4}$} \\
\hline Cálcio (\%) & 0,700 & 0,700 & 0,700 & 0,700 & 0,700 & 0,700 \\
\hline $\begin{array}{l}\text { Energia metabolizável } \\
\text { (Mcal/kg) }\end{array}$ & 3,182 & 3,182 & 3,182 & 3,182 & 3,182 & 3,182 \\
\hline Proteína bruta (\%) & 16,098 & 16,098 & 16,098 & 16,098 & 19,439 & 19,439 \\
\hline Fósforo disponível (\%) & 0,320 & 0,320 & 0,320 & 0,320 & 0,320 & 0,320 \\
\hline Lisina digestível (\%) & 0,875 & 0,875 & 0,875 & 0,875 & 0,875 & 0,875 \\
\hline $\begin{array}{l}\text { Metionina+cistina } \\
\text { digestível (\%) }\end{array}$ & 0,493 & 0,493 & 0,498 & 0,498 & 0,565 & 0,565 \\
\hline Treonina digestível (\%) & 0,516 & 0,516 & 0,542 & 0,542 & 0,629 & 0,629 \\
\hline Triptofano digestível (\%) & 0,159 & 0,159 & 0,159 & 0,159 & 0,207 & 0,207 \\
\hline Ractopamina (ppm) & $\mathbf{0 , 0 0}$ & 5,00 & $\mathbf{0 , 0 0}$ & 5,00 & $\mathbf{0 , 0 0}$ & 5,00 \\
\hline
\end{tabular}

${ }^{1}$ Níveis de garantia (por kg do produto): ácido fólico, 116,55mg; ácido pantotênico, 2.333,5mg; biotina, 5,28mg; niacina, 5.600mg; piridoxina, $175 \mathrm{mg}$; riboflavina, 933,3mg; tiamina, $175 \mathrm{mg}$; vitamina A, $1.225 .000 \mathrm{UI}$; vitamina $\mathrm{D}_{3}$, 315.000UI; vitamina E, $1.400 \mathrm{mg}$; vitamina $\mathrm{K}_{3}$, 700mg; vitamina $\mathrm{B}_{12}, 6.825 \mathrm{mg}$; selênio, 105mg; antioxidante $1.500 \mathrm{mg}$.

${ }^{2}$ Níveis de garantia (por kg do produto): cálcio, 98.800mg; cobalto, 185mg; cobre, 15,750mg; ferro, 26.250mg; iodo, 1.470mg; manganês, 41.850mg; zinco, 77.999mg.

${ }^{3}$ Níveis de garantia (por kg do produto): cobre, $150 \mathrm{mg}$; zinco, $100 \mathrm{mg}$.

${ }^{4}$ Segundo Rostagno et al. (2000).

Na avaliação das carcaças in vivo, foram tomadas medidas nos animais individualmente, no início, aos 21 dias e aos 28 dias de experimento, após as pesagens dos animais, utilizando-se equipamento portátil de ultrassom (PigLog- $105^{\circledR}$ ). As medidas ultrassônicas efetuadas foram: ponto $\mathrm{P}_{1}-$ 
medido a $6,5 \mathrm{~cm}$ da linha dorsolombar e a $6,5 \mathrm{~cm}$ da última costela na direção caudal $\left(\mathrm{ET}-\mathrm{P}_{1}\right)$; ponto $\mathrm{P}_{2}$ - medido a $6,5 \mathrm{~cm}$ da linha dorsolombar e a $6,5 \mathrm{~cm}$ da última costela na direção cranial $\left(\right.$ ET- $\mathrm{P}_{2}$ e a medida de profundidade de lombo (PL); porcentagem de carne magra (PCM) - os preditores utilizados pelo aparelho para estimar o rendimento de carne magra foram a espessura de toucinho (nos pontos 1 e 2) e a profundidade de lombo, sendo os pontos de leitura do aparelho obtidos sempre do lado esquerdo do animal. A partir dos valores de leitura, determinou-se a porcentagem de carne magra. A taxa de deposição de carne magra diária (TDCMD) foi obtida dividindo-se a diferença entre a porcentagem de carne magra estimada no último dia e a porcentagem de carne magra no primeiro dia pelo número de dias em experimento.

Ao final do período experimental, os animais foram pesados e permaneceram em jejum alimentar por aproximadamente 18 horas. Posteriormente, foram pesados novamente e encaminhados para abate no Frigorífico Industrial Vale do Piranga (FRIVAP), localizado no município de Ponte Nova, MG. Os animais foram atordoados, abatidos, depilados, eviscerados e submetidos à avaliação das características de carcaça de acordo com os procedimentos do frigorífico.

Nas carcaças, foram aferidos rendimento de carne e espessura de toucinho por meio de aparelho de tipificação de carcaça (GP-4 Henessy Nova Zelândia - Solft Didai). A espessura de toucinho e a profundidade de lombo foram medidas em uma das meias-carcaças, no ponto correspondente à projeção perpendicular da última costela sobre o músculo Longuíssimos dorsi a $4 \mathrm{~cm}$ da coluna vertebral. Com os dados de espessura de toucinho e da profundidade de lombo, foi calculada a porcentagem de carne magra da carcaça segundo a equação contida no software do aparelho.

Em relação às características de carcaça, avaliaram-se o peso da carcaça quente, o rendimento de carcaça, o peso da carcaça fria, o rendimento de pernil, o rendimento de carré, a espessura de toucinho, a profundidade de lombo e a porcentagem de carne magra. $\mathrm{O}$ rendimento de pernil e o de carré foram obtidos pela relação percentual entre o peso da carcaça resfriada e o peso dos dois pernis e dos dois carrés somados, respectivamente.

Os dados de desempenho, das medidas de ultrassom in vivo e das características de carcaça foram submetidos à análise de variância utilizando-se o pacote computacional SAEG (Sistemas..., 2000). Para os resultados das medidas de ultrassom in vivo (espessura de toucinho, profundidade de lombo e porcentagem de carne magra), utilizou-se como covariável o resultado correspondente da mesma variável no início do experimento. Havendo interação significativa, comparou-se cada método de formulação dentro de cada nível de ractopamina, pelo teste de Duncan, a 5\% de probabilidade.

\section{RESULTADOS E DISCUSSÃO}

Os resultados de consumo de ração, consumo de lisina digestível diário, ganho de peso diário aos 21 e 28 dias, e peso corporal aos 28 dias de tratamento, em função do método de formulação de dieta, estão apresentados na Tab. 2.

Tabela 2. Desempenho de leitoas em terminação, submetidas a três metodologias de formulação de ração, durante 21 e 28 dias

\begin{tabular}{lcccc}
\multicolumn{1}{c}{ Parâmetro } & Proteína ideal & $\begin{array}{c}\text { Sem ajuste } \\
\text { aminoácidos }\end{array}$ & $\begin{array}{c}\text { Alta proteína } \\
\text { bruta }\end{array}$ & $\begin{array}{c}\text { CV } \\
(\%)\end{array}$ \\
\hline & & 21 dias de tratamento & \\
Consumo de ração (kg/dia) & $2,66 \mathrm{~b}$ & $2,64 \mathrm{~b}$ & $2,84 \mathrm{a}$ & 5,5 \\
Consumo de lisina digestível (g/dia) & $23,3 \mathrm{~b}$ & $23,1 \mathrm{~b}$ & $24,8 \mathrm{a}$ & 5,5 \\
\hline & & 28 dias de tratamento & \\
Consumo de ração (kg/dia) & $2,71 \mathrm{~b}$ & $2,74 \mathrm{~b}$ & $2,89 \mathrm{a}$ & 5,6 \\
Consumo de lisina digestível (g/dia) & $23,7 \mathrm{~b}$ & $23,9 \mathrm{~b}$ & $25,3 \mathrm{a}$ & 5,6 \\
Ganho de peso (kg/dia) & $1,06 \mathrm{~b}$ & $1,06 \mathrm{~b}$ & $1,21 \mathrm{a}$ & 6,9 \\
Peso corporal final (kg) & $114,44 \mathrm{~b}$ & $114,04 \mathrm{~b}$ & $118,95 \mathrm{a}$ & 5,6 \\
\hline
\end{tabular}

Médias seguidas de letras distintas na linha diferem $(\mathrm{P}<0,05)$ entre si pelo teste $\mathrm{F}$. 
O consumo diário de ração foi aproximadamente $7 \%$, mais alto $(\mathrm{P}<0,05)$ nos animais que receberam a ração formulada com alta proteína bruta em relação à média dos outros dois tratamentos aos 21 e 28 dias. Mitchell et al. (1991) também encontraram maior consumo de ração em suínos alimentados com dietas que continham o teor mais elevado de $\mathrm{PB}$. O consumo de lisina digestível foi maior $(\mathrm{P}<0,05)$ quando os animais foram alimentados com dieta formulada com alta PB aos 21 e 28 dias. Uma vez que as rações eram isolisínicas, pode-se inferir que o maior consumo de ração proporcionou maior consumo de lisina.

Aos 28 dias, as leitoas que consumiram ração formulada com alta $\mathrm{PB}$ apresentaram maior $(\mathrm{P}<0,01)$ ganho de peso diário $(150 \mathrm{~g} /$ dia a mais que a média dos outros dois grupos). Efeito semelhante foi observado sobre o peso final, que foi $4,7 \mathrm{~kg}$ mais alto $(\mathrm{P}<0,01)$ para o tratamento com alta PB, correspondendo a um aumento de aproximadamente $7 \%$ no peso corporal das leitoas, ao final dos 28 dias de experimento. Marinho et al. (2005a) não observaram diferenças significativas do método de formulação sobre o ganho de peso diário e no peso corporal dos animais. Devido ao menor consumo de dieta, leitoas exigem níveis mais elevados de aminoácidos quando comparadas aos machos castrados. Dessa forma, pode-se deduzir que a dieta formulada com alta proteína bruta parece atender melhor às exigências de leitoas em terminação, provavelmente em razão dos maiores níveis de aminoácidos essenciais que são proporcionados por esse método de formulação.
Constatou-se interação $(\mathrm{P}<0,05)$ de métodos de formulação de ração versus suplementação de ractopamina para ganho de peso e peso corporal aos 21 dias e para conversão alimentar aos 21 e 28 dias de experimento. Os resultados de CRD, CLD, GPD e peso corporal de leitoas, após 21 e 28 dias de suplementação com 0 e 5ppm de ractopamina na ração, estão apresentados na Tab. 3.

O consumo de ração e de lisina digestível diário não foi influenciado $(\mathrm{P}>0,05)$ pela suplementação com ractopamina aos 21 ou 28 dias (Tab. 3). Marinho et al. (2005b) também não encontraram efeito significativo da suplementação de ractopamina (5ppm) sobre o consumo de ração e de lisina diário para suínos machos castrados. Entretanto Mitchell et al. (1991) observaram redução de 10\% no consumo de ração de suínos em terminação consumindo dietas suplementadas com 20ppm de ractopamina.

Animais que consumiram ração suplementada durante 28 dias tiveram aumento de 5\% no GPD em relação aos animais não suplementados. Resultados semelhantes foram obtidos por Marinho et al. (2005a), que observaram aumento significativo no ganho de peso em suínos machos castrados que consumiram ração com 5pm de ractopamina. Os efeitos dos métodos de formulação e da ractopamina sobre o ganho de peso diário das leitoas, aos 21 dias de tratamento, são apresentados na Tab. 4.

Tabela 3. Desempenho de leitoas em terminação suplementadas ou não com ractopamina, durante 21 e 28 dias

\begin{tabular}{lccc}
\hline \multirow{2}{*}{ Parâmetro } & \multicolumn{2}{c}{ Ractopamina } & CV \\
\cline { 2 - 3 } & 0ppm & 5ppm & $(\%)$ \\
\hline Consumo de ração (kg/dia) & & 21 dias de tratamento & \\
Consumo de lisina digestível (g/dia) & 2,73 & 2,70 & 5,5 \\
& 23,9 & 23,6 & 5,5 \\
\hline & & 28 dias de tratamento & \\
Consumo de ração (kg/dia) & 2,80 & 2,76 & 5,6 \\
Gansumo de lisina digestível (g/dia) & 24,5 & 24,2 & 5,6 \\
Peso corporal final (kg) & $1,08 \mathrm{~b}$ & $1,14 \mathrm{a}$ & 6,9 \\
\hline
\end{tabular}

Médias seguidas de letras distintas na linha diferem $(\mathrm{P}<0,05)$ entre si pelo teste Duncan. 


\section{Pereira et al.}

Tabela 4. Ganho de peso diário de leitoas em terminação que consumiram dietas suplementadas ou não com ractopamina, durante 21 dias

\begin{tabular}{|c|c|c|}
\hline \multirow{2}{*}{ Método de formulação } & \multicolumn{2}{|c|}{ Ractopamina } \\
\hline & 0ppm & 5ppm \\
\hline Proteína ideal & $1,12 \mathrm{Ab}$ & $1,05 \mathrm{Bb}$ \\
\hline Sem ajuste de aminoácidos & $0,99 \mathrm{Bb}$ & $1,12 \mathrm{Ba}$ \\
\hline Alta proteína bruta & 1,18Aa & $1,26 \mathrm{Aa}$ \\
\hline CV (\%) & & \\
\hline
\end{tabular}

Médias seguidas de letras distintas, minúsculas na linha e maiúsculas na coluna, diferem $(\mathrm{P}<0,05)$ entre si pelo teste Duncan.

O ganho de peso obtido pelas dietas formuladas com base na proteína ideal e alta $\mathrm{PB}$, sem ractopamina, foi semelhante. Estes resultados foram mais elevados que os obtidos pela formulação sem ajuste de aminoácidos para proteína ideal. Pode-se deduzir que a dieta sem ajuste de aminoácidos para o conceito de proteína ideal não atendeu às exigências de desempenho de leitoas em terminação quando a dieta não foi suplementada com ractopamina.

Verificou-se, que com a suplementação de ractopamina, a dieta formulada com alta PB proporcionou aumento no ganho de peso das leitoas em relação às formuladas com ou sem ajuste de aminoácidos para proteína ideal. Este resultado corrobora a afirmativa de que a relação proposta para proteína ideal pode não atender às exigências de suínos suplementados com ractopamina. A dieta formulada com alta inclusão de farelo de soja apresentou relação de 64,72 e $24 \%$, respectivamente, para metionina + cistina, treonina e triptofano digestível em relação à lisina digestível, enquanto a ração formulada para proteína ideal possuía 62\%, 57\% e $18 \%$ para metionina + cistina, treonina e triptofano, respectivamente. Resultados semelhantes foram obtidos por Xiao et al. (1999), que também encontraram interação significativa do maior nível de $\mathrm{PB}$ versus suplementação de ractopamina para ganho de peso. Marinho et al. (2005b), ao utilizarem suínos machos castrados, não encontraram interação significativa de ractopamina versus métodos de formulação da dieta para o ganho de peso.

O efeito do método de formulação da dieta e da ractopamina sobre o peso corporal das leitoas até os 21 dias de tratamento são apresentados na Tab. 5. As leitoas que consumiram dieta formulada com alta PB apresentaram aumento no peso final de $4 \mathrm{~kg}$ em relação à média dos outros dois grupos quando suplementadas com 5pm de ractopamina. Os resultados de conversão alimentar em função dos métodos de formulação e da ractopamina, aos 21 e 28 dias de tratamento, são apresentados na Tab. 6.

Tabela 5. Peso corporal de leitoas em terminação alimentadas com dietas suplementadas ou não com ractopamina, durante 21 dias

\begin{tabular}{|c|c|c|}
\hline \multirow{2}{*}{ Método de formulação } & \multicolumn{2}{|c|}{ Ractopamina } \\
\hline & 0ppm & 5ppm \\
\hline Proteína ideal & 108,49Aа & $107,00 \mathrm{Ba}$ \\
\hline Sem ajuste de aminoácidos & $105,81 \mathrm{Bb}$ & $108,05 \mathrm{Ba}$ \\
\hline Alta proteína bruta & $110,26 \mathrm{Aa}$ & $111,52 \mathrm{Aa}$ \\
\hline CV (\%) & & \\
\hline
\end{tabular}

Médias seguidas de letras distintas, minúsculas na linha e maiúsculas na coluna, diferem $(\mathrm{P}<0,05)$ entre si pelo teste Duncan.

A conversão alimentar foi semelhante para as leitoas alimentadas com a dieta formulada com ajuste dos aminoácidos para proteína ideal, quando submetidas à suplementação ou não da ractopamina, aos 21 e 28 dias de tratamento. Os animais alimentados com a dieta sem o ajuste para proteína ideal e os alimentados com dieta formulada com alta proteína bruta melhoraram a conversão alimentar quando foram suplementados com ractopamina na dosagem de 5ppm aos 21 e 28 dias de tratamento.

Entre os animais tratados com ractopamina, observou-se melhor conversão alimentar para aqueles alimentados com a dieta formulada com alta PB tanto aos 21 quanto aos 28 dias. Para os 
animais não tratados com ractopamina, não foi verificada diferença $(\mathrm{P}>0,05)$ para conversão alimentar entre as três metodologias de formulação de dieta até 21 dias de tratamento. Entretanto, ao final dos 28 dias, houve piora da conversão alimentar no grupo alimentado com a dieta sem ajuste para proteína ideal em relação às outras duas metodologias. Marinho et al. (2005a) não verificaram efeito significativo dos métodos de formulação sobre o ganho de peso e a conversão alimentar.

Tabela 6. Conversão alimentar de leitoas em terminação alimentadas com dietas suplementadas ou não com ractopamina, durante 21 e 28 dias

\begin{tabular}{lcrcc}
\hline \multirow{2}{*}{ Método de formulação } & \multicolumn{2}{c}{21 dias } & \multicolumn{2}{c}{28 dias } \\
\cline { 2 - 5 } & \multicolumn{2}{c}{ Ractopamina } & Ractopamina \\
\cline { 2 - 5 } & 0ppm & 5ppm & 0ppm & $5 p p m$ \\
\hline Proteína ideal & $2,40 \mathrm{Aa}$ & $2,56 \mathrm{Aa}$ & $2,54 \mathrm{Ba}$ & $2,59 \mathrm{Aa}$ \\
Sem ajuste de aminoácidos & $2,63 \mathrm{Aa}$ & $2,39 \mathrm{Ab}$ & $2,73 \mathrm{Aa}$ & $2,46 \mathrm{Ab}$ \\
Alta proteína bruta & $2,49 \mathrm{Aa}$ & $2,19 \mathrm{Bb}$ & $2,54 \mathrm{Ba}$ & $2,28 \mathrm{Bb}$ \\
CV (\%) & \multicolumn{2}{c}{7,0} & & \multicolumn{2}{c}{5,2} \\
\hline
\end{tabular}

Médias seguidas de letras distintas, minúsculas na linha e maiúsculas na coluna, diferem $(\mathrm{P}<0,05)$ entre si pelo teste Duncan.

No presente trabalho, CA, GPD e peso corporal dos animais alimentados com a dieta formulada com alta proteína bruta apresentaram os melhores resultados, sugerindo não haver excesso de aminoácidos na ração formulada com alta PB, mas sim melhor adequação da relação entre os aminoácidos na dieta.

Fernandez et al. (2004), ao trabalharem com diferentes relações treonina digestível:lisina digestível e dois níveis de ractopamina (5 e 10ppm) para suínos em terminação, estabeleceram que a relação de treonina digestível com a lisina digestível deve ser de, aproximadamente, $70 \%$ para animais que consumirem dieta suplementada com ractopamina, nível próximo ao utilizado no tratamento com alta PB no presente trabalho. Vários trabalhos estabeleceram exigência de treonina acima daquela recomendada por PIC (1999), mesmo quando não foram suplementados com ractopamina (Rostagno et al., 2005).

Os resultados da avaliação das carcaças obtidas in vivo por ultrassom, aos 21 e 28 dias de tratamento, em função de três métodos de formulação da dieta, para leitoas a partir dos 85kg, estão apresentados na Tab. 7. Não houve interação $(\mathrm{P}>0,05)$ nível de ractopamina versus métodos de formulação sobre os parâmetros de carcaça avaliados in vivo. Não houve efeito $(\mathrm{P}>0,05)$ dos métodos de formulação sobre a espessura de toucinho em P1 e P2, profundidade de lombo, rendimento de pernil, rendimento de carré e rendimento em carne magra na carcaça aos 21 e 28 dias de experimento. Marinho et al. (2005b) também não observaram efeitos dos métodos de formulação da dieta sobre os parâmetros de carcaça avaliados por ultrassom, em suínos machos castrados, tratados com três métodos de formulação da dieta.

A taxa de deposição de carne magra na carcaça das leitoas foi influenciada $(\mathrm{P}<0,05)$ pelos métodos de formulação de dieta aos 28 dias de experimento. Leitoas alimentadas com ração formulada com alta PB apresentaram uma TDCM 101g/dia superior em relação aos demais tratamentos. De acordo com este resultado, podese ver que relações mais altas de alguns aminoácidos essenciais com a lisina, principalmente a treonina, foram mais eficientes em atender às exigências de leitoas em terminação.

Os resultados de características de carcaça avaliadas in vivo aos 21 e 28 dias e da taxa de deposição de carne magra na carcaça aos 28 dias de leitoas suplementadas ou não com ractopamina estão apresentados na Tab. 8. Houve interação $(\mathrm{P}<0,01)$ nível de ractopamina versus método de formulação sobre a taxa de deposição de carne magra na carcaça das leitoas, aos 21 dias. Observou-se efeito $(\mathrm{P}<0,05)$ da ractopamina sobre a espessura de toucinho medida no ponto $\mathrm{P} 2$, a profundidade de lombo e a porcentagem de carne magra na carcaça $(\mathrm{P}<0,01)$, aos 21 e 28 dias, e sobre a taxa de deposição de carne magra $(\mathrm{P}<0,05)$ aos 28 dias. 


\section{Pereira et al.}

Tabela 7. Características de carcaça, obtidas in vivo, de leitoas em terminação, submetidas a três métodos de formulação de ração, durante 21 e 28 dias

\begin{tabular}{lcccc}
\hline Parâmetro & $\begin{array}{c}\text { Proteína } \\
\text { ideal }\end{array}$ & $\begin{array}{c}\text { Sem ajuste de } \\
\text { aminoácidos }\end{array}$ & $\begin{array}{c}\text { Alta proteína } \\
\text { bruta }\end{array}$ & $\begin{array}{c}\text { CV } \\
(\%)\end{array}$ \\
\hline & \multicolumn{4}{c}{21 dias de tratamento } \\
Espessura de toucinho, ponto P1 (mm) & 1 & 13,3 & 13,2 & 11,3 \\
Espessura de toucinho, ponto P2 (mm) $^{1}$ & 13,1 & 10,5 & 10,3 & 10,7 \\
Profundidade de lombo (mm) $^{1}$ & 10,4 & 56,4 & 56,8 & 5,9 \\
Rendimento em carne magra (\%) $^{1}$ & 56,5 & 59,8 & 59,9 & 2,0 \\
\hline & 60,0 & 28 dias de tratamento \\
Espessura de toucinho, ponto P1 (mm) $^{1}$ & 13,6 & 13,6 & 14,0 & 12,4 \\
Espessura de toucinho, ponto P2 (mm) $^{1}$ & 11,1 & 10,8 & 11,0 & 12,2 \\
Profundidade de lombo (mm) $^{1}$ & 58,1 & 57,7 & 60,2 & 7,0 \\
Rendimento em carne magra (\%) $^{1}$ & 59,6 & 59,6 & 59,7 & 2,0 \\
Taxa de deposição de carne magra (g/dia) & $593,6 \mathrm{~b}$ & $654,4 \mathrm{~b}$ & $725,4 \mathrm{a}$ & 11,1 \\
\hline
\end{tabular}

${ }^{1}$ Medidas ajustadas de acordo com a covariável - valor correspondente à mesma variável no início do experimento. Médias seguidas de letras distintas na linha diferem $(\mathrm{P}<0,05)$ entre si pelo teste $\mathrm{F}$.

Tabela 8. Características de carcaça, obtidas in vivo, de leitoas em terminação, suplementadas ou não com ractopamina, durante 21 e 28 dias

\begin{tabular}{lccc}
\hline \multicolumn{1}{c}{ Parâmetro } & \multicolumn{2}{c}{ Ractopamina } & CV \\
\cline { 2 - 4 } & 0ppm & 5ppm & $(\%)$ \\
\hline Espessura de toucinho, ponto P1 (mm) $^{1}$ & 13,4 & 21 dias de tratamento \\
Espessura de toucinho, ponto P2 (mm) $^{1}$ & $10,7 \mathrm{~b}$ & 13,0 & 11,3 \\
Profundidade de lombo (mm) $^{1}$ & $55,1 \mathrm{~b}$ & $10,1 \mathrm{a}$ & 10,7 \\
Rendimento em carne magra (\%) $^{1}$ & $59,5 \mathrm{~b}$ & $58,0 \mathrm{a}$ & 2,5 \\
\hline Espessura de toucinho, ponto P1 (mm) $^{1}$ & \multicolumn{3}{c}{ 28 dias de tratamento } \\
Espessura de toucinho, ponto P2 (mm) $^{1}$ & 14,0 & 13,5 & 12,4 \\
Profundidade de lombo (mm) $^{1}$ & $11,5 \mathrm{~b}$ & $10,4 \mathrm{a}$ & 12,2 \\
Rendimento em carne magra (\%) $^{1}$ & $57,2 \mathrm{~b}$ & $60,2 \mathrm{a}$ & 7,0 \\
Taxa de deposição de carne magra (g/dia) & $59,1 \mathrm{~b}$ & $60,2 \mathrm{a}$ & 2,0 \\
\hline
\end{tabular}

${ }^{1}$ Medidas ajustadas de acordo com a covariável - valor correspondente à mesma variável no início do experimento. Médias seguidas de letras distintas na linha diferem $(\mathrm{P}<0,05)$ entre si pelo teste $\mathrm{F}$.

A suplementação de ractopamina melhorou a carcaça dos animais por proporcionar redução na espessura de toucinho, aumento na profundidade do lombo e do rendimento em carne magra da carcaça. Estes resultados estão de acordo com os encontrados por See et al. (2004), que verificaram aumento da área do olho de lombo e redução da espessura de toucinho nos animais suplementados com ractopamina, independentemente do plano de utilização do produto. Xiao et al. (1999) também observaram aumento de $4,5 \%$ na porcentagem de carne magra na carcaça, de $4 \%$ na área de olho de lombo, e redução da gordura corporal com a suplementação das dietas com 20ppm de ractopamina. Os resultados da taxa de deposição de carne magra na carcaça das leitoas aos 21 dias estão apresentados na Tab. 9.
Sem a suplementação com ractopamina, todas as dietas foram semelhantes. Quando suplementada a dieta com ractopamina, a melhor taxa de deposição de carne magra na carcaça ocorreu no grupo de animais alimentados com a dieta com alta PB. Já os animais do grupo sem ajuste de aminoácidos para proteína ideal apresentaram resultados inferiores aos animais que consumiram dieta formulada com alta PB e àqueles que consumiram ração com ajuste de aminoácidos para proteína ideal. Mais uma vez, a ração formulada com alta proteína bruta foi a que melhor atendeu às exigências de leitoas em terminação. A maior taxa de deposição de carne magra na carcaça remete a um perfil de crescimento redirecionado para a hipertrofia muscular em detrimento do acúmulo de gorduras. 
Efeito da ractopamina...

Tabela 9. Taxa de deposição de carne magra na carcaça, de leitoas em terminação, submetidas a três métodos de formulação de ração e suplementadas ou não com ractopamina, durante 21 dias

\begin{tabular}{|c|c|c|}
\hline \multirow{2}{*}{ Método de formulação } & \multicolumn{2}{|c|}{ Ractopamina } \\
\hline & 0ppm & $5 p p m$ \\
\hline Proteína ideal & $636,06 \mathrm{Aa}$ & $605,61 \mathrm{Ba}$ \\
\hline Sem ajuste de aminoácidos & $585,57 \mathrm{Bb}$ & $722,33 \mathrm{ABa}$ \\
\hline Alta proteína bruta & $712,69 \mathrm{Aa}$ & $784,41 \mathrm{Aa}$ \\
\hline CV (\%) & & \\
\hline
\end{tabular}

Medidas ajustadas de acordo com a covariável - valor correspondente à mesma variável no início do experimento. Médias seguidas de letras distintas, minúsculas na linha e maiúsculas na coluna, diferem $(\mathrm{P}<0,05)$ entre si pelo teste Duncan.

Ao se associarem os resultados de deposição de carne magra na carcaça com o de GPD e o peso final das leitoas e CA, pode-se inferir que o aumento no ganho de peso e a melhoria da CA ocorreram em razão do aumento da taxa de deposição de carne magra. Assim, os animais suplementados com ractopamina apresentaram melhor partição dos nutrientes durante o metabolismo e isso proporcionou maior ganho de tecido magro. Houve aumento na PL e na porcentagem de carne magra na carcaça e redução na espessura de toucinho medida no ponto P2.

Os resultados de rendimento de carcaça, rendimento de pernil, rendimento de carré, espessura de toucinho, profundidade de lombo e porcentagem de carne magra na carcaça em função dos métodos de formulação das dietas encontram-se na Tab. 10. Não houve interação $(\mathrm{P}>0,05)$ métodos de formulação e ractopamina da dieta sobre os resultados de avaliação da carcaça.

Tabela 10. Características de carcaça de leitoas em terminação, submetidas a três métodos de formulação de ração, durante 28 dias

\begin{tabular}{lcccc}
\hline Parâmetro & Proteína ideal & $\begin{array}{c}\text { Sem ajuste de } \\
\text { aminoácidos }\end{array}$ & $\begin{array}{c}\text { Alta proteína } \\
\text { bruta }\end{array}$ & $\begin{array}{c}\text { CV } \\
(\%)\end{array}$ \\
\hline Rendimento carcaça (\%) & 71,9 & 72,9 & 72,7 & 3,2 \\
Rendimento pernil (\%) & 34,9 & 35,1 & 34,8 & 3,2 \\
Rendimento carré (\%) & 13,0 & 13,0 & 12,9 & 5,3 \\
Espessura toucinho (mm) & $13,1 \mathrm{a}$ & $11,5 \mathrm{~b}$ & $12,0 \mathrm{ab}$ & 16,6 \\
Profundidade de lombo (mm) & 67,14 & 70,2 & 67,6 & 9,7 \\
Rendimento em carne magra (\%) & $58,3 \mathrm{~b}$ & $59,8 \mathrm{a}$ & $59,0 \mathrm{ab}$ & 2,7 \\
\hline
\end{tabular}

Médias seguidas de letras distintas na linha diferem entre si pelo teste $\mathrm{F}(\mathrm{P}<0,05)$.

Não houve efeito $(\mathrm{P}>0,05)$ dos métodos de formulação de ração sobre o rendimento de carcaça, o rendimento de pernil, o rendimento de carré e a profundidade de lombo. Marinho et al. (2005b) também não observaram efeito significativo do método de formulação de ração sobre os parâmetros de carcaça avaliados em frigorífico, quando utilizaram suínos machos castrados em terminação.

A espessura de toucinho medida na altura da décima costela e o rendimento em carne magra da carcaça foram melhores $(\mathrm{P}<0,05)$ nos animais alimentados com dieta sem ajuste de aminoácidos para a proteína ideal, enquanto aqueles suplementados com dieta com alta PB apresentaram resultados intermediários. Estes resultados diferem dos obtidos in vivo, em que os melhores resultados ocorreram no grupo tratado com alta PB.

Os efeitos da ractopamina sobre o rendimento de carcaça, o rendimento de pernil, o rendimento de carré, a profundidade de lombo, a espessura de toucinho e o rendimento em carne magra na carcaça de leitoas a partir de 85kg encontram-se na Tab. 11. Não houve efeito $(\mathrm{P}>0,05)$ da suplementação de ractopamina sobre 0 rendimento de carcaça, rendimento de pernil e a profundidade de lombo. Resultados semelhantes foram encontrados por Armstrong et al. (2004), que observaram aumento do peso da carcaça, em função do maior peso final dos animais, mas não verificaram aumento no rendimento destas. Da 
mesma forma, Budiño et al. (2005), ao avaliarem carcaças de suínos que consumiram dieta suplementada com diferentes níveis e fontes de ractopamina, verificaram que as carcaças foram aproximadamente $5 \%$ mais pesadas que as do tratamento controle, sem alteração em seu rendimento.

Marinho et al. (2005b), entretanto, ao utilizarem suínos machos castrados e tratamentos idênticos aos do presente trabalho, não observaram efeito da ractopamina sobre a maioria dos parâmetros de carcaça avaliados em frigorífico, exceto para o rendimento de pernil, que foi $3,4 \%$ maior, e a profundidade de lombo para o grupo tratado com ractopamina (5ppm). O aumento do rendimento de pernil também foi encontrado por Uttaro et al. (1996), que observaram aumento de 7\%. No entanto, Budiño et al. (2005) não observaram efeito para o peso do pernil. A espessura de toucinho, medida na altura da décima costela, o rendimento de carré e o rendimento em carne magra da carcaça foram melhorados nos animais tratados com ractopamina. Da mesma forma, Budiño et al. (2005) encontraram redução na espessura de toucinho e aumento na porcentagem de carne magra na carcaça.

Tabela 11. Características de carcaça de leitoas em terminação consumindo ração suplementada ou não com ractopamina, durante 28 dias

\begin{tabular}{lccc}
\hline \multirow{2}{*}{ Parâmetro } & \multicolumn{2}{c}{ Ractopamina } & CV \\
\cline { 2 - 3 } & $0 \mathrm{ppm}$ & $5 \mathrm{ppm}$ & $(\%)$ \\
\hline Rendimento carcaça (\%) & 72,70 & 72,31 & 3,2 \\
Rendimento pernil (\%) & 34,70 & 35,10 & 3,2 \\
Rendimento carré (\%) & $12,80 \mathrm{~b}$ & $13,10 \mathrm{a}$ & 5,3 \\
Espessura toucinho (mm) & $12,90 \mathrm{~b}$ & $11,50 \mathrm{a}$ & 16,6 \\
Profundidade de lombo (mm) & 67,88 & 68,76 & 9,7 \\
Rendimento em carne magra (\%) & $58,54 \mathrm{~b}$ & $59,57 \mathrm{a}$ & 2,7 \\
\hline
\end{tabular}

Médias seguidas de letras distintas na linha diferem $(\mathrm{P}<0,05)$ entre si pelo teste $\mathrm{F}$.

\section{CONCLUSÕES}

A suplementação com ractopamina de dietas para leitoas em terminação melhora o desempenho e a qualidade da carcaça por proporcionar aumento do ganho de peso diário, da profundidade do lombo, do rendimento de carré e do rendimento em carne magra na carcaça e redução da conversão alimentar e da espessura de toucinho. Dietas formuladas com alta proteína bruta, por meio da adição do farelo de soja, proporcionam melhores resultados de desempenho e taxa de deposição de carne magra na carcaça em leitoas em terminação suplementadas com ractopamina.

\section{REFERÊNCIAS BIBLIOGRÁFICAS}

ARMSTRONG, T.A.; IVERS, D.J.; WAGNER, J.R. et al. The effectof dietary ractopamine concentration and duration of feeding on growth performance, carcass characteristics and meat quality of finishing pigs. J. Anim. Sci., v.82, p.3245-3253, 2004.
BUDIÑO, F.E.L.; THOMAZ, M.C.; NEME, R. et al., Efeito da adição de diferentes níveis e fontes de cloridrato de ractopamina sobre o desempenho e características da carcaça de suínos em terminação. In: CONGRESSO BRASILEIRO DE VETERINÁRIOS ESPECIALISTAS EM SUÍNOS, 12., 2005, Fortaleza. Anais... Fortaleza, 2005. p.333-334.

FERNANDEZ, D.M.; ROSAS, N.; SORIA, A.I. et al. Threonine to lysine ratio in ractopamine treated pigs. Poult. Sci., v.83, suppl.1, p.98-99, 2004.

MARINHO, P.C.; FONTES, D.O.; SILVA, F.C.O. et al. Efeito da ractopamina e de métodos de formulação sobre o desempenho de suínos machos castrados em terminação. In: CONGRESSO BRASILEIRO DE VETERINÁRIOS ESPECIALISTAS EM SUÍNOS, 12., 2005, Fortaleza. Anais... Fortaleza, 2005a. p.341-342. 
MARINHO, P.C.; FONTES, D.O.; PEREIRA, F.A. et al. Efeito da ractopamina e de métodos de formulação sobre as características de carcaça de suínos machos castrados em terminação. In: CONGRESSO BRASILEIRO DE VETERINÁRIOS ESPECIALISTAS EM SUÍNOS, 12., 2005, Fortaleza. Anais... Fortaleza, 2005b. p.343-344.

MITCHELL, A.D.; SOLOMON, M.B.; STEELE, N.C. Influence of level of dietary protein or energy on effects of ractopamine in finishing swine. J. Anim. Sci., v.69, p.4487-4495, 1991.

PIC. Grow - finish nutrition concepts: impact of nutrition on lean growth. Technical Update, v.2, n.1, 1999. 18p.

ROSTAGNO, H.S.; ALBINO, L.F.T.; DONZELE, J.L. et al. Tabelas brasileiras para aves e suínos - composição de alimentos e exigências nutricionais. Viçosa: UFV, 2000. 141p.

ROSTAGNO, H.S.; ALBINO, L.F.T.; DONZELE, J.L. et al. Tabelas brasileiras para aves e suínos - composição de alimentos e exigências nutricionais. Viçosa: UFV, 2005. 186p.
SEE, M.T.; ARMSTRONG, T.A.; WELDON, W.C. Effect of ractopamine feeding program on growth performance and carcass composition in finishing pigs. J. Anim. Sci., v.82, p.2474-2480, 2004.

SCHINCKEL, A.P.; RICHERT, B.T.; HERR, C.T. et al. Development of a model to describe the compositional growth and ietary lysine requirements of pigs fed ractopamine. J. Anim. Sci., v.81, p.1106-1119, 2003.

SISTEMAS de análises estatísticas e genéticas. SAEG, Versão 8.0. Viçosa: UFV, 2000.

UTTARO, B.E.; BALL, R.O.; DICK, P. et al. Effect of ractopamine and sex on growth, carcass characteristics, processing yield, and meat quality characteristics of crossbred swine. $J$. Anim. Sci., v.71, p.2439-2449, 1996.

XIAO, R.J.; XU, Z.R.; CHEN, H.L. Effects of ractopamine at different dietary protein levels on growth performance and carcass characteristics in finishing pigs. Anim. Feed Sci. Technol., v.79, p.119-127, 1999. 